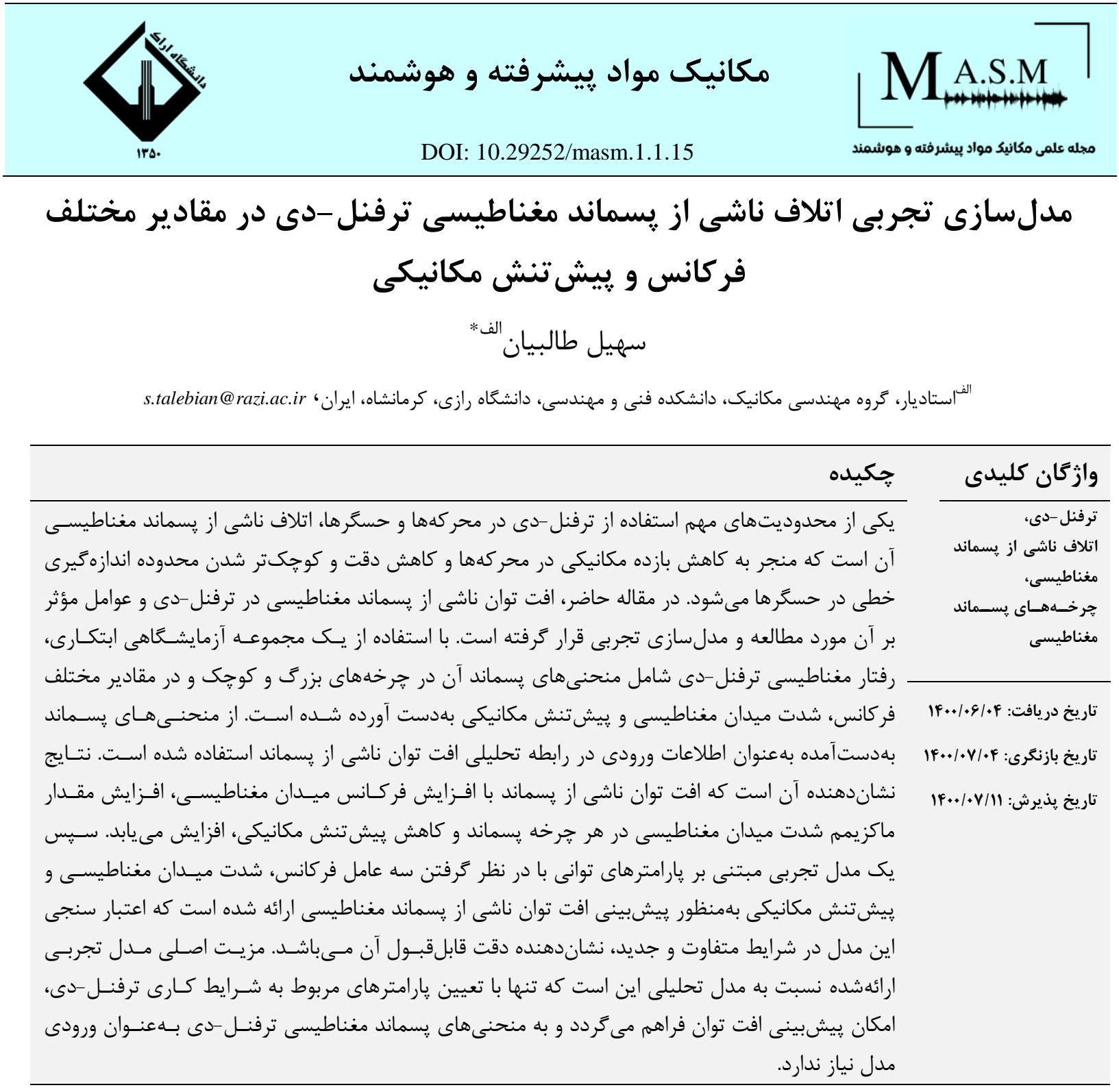

\title{
Experimental modeling of Magnetic Hysteresis Power Loss of Terfenol-D at Different Values of Frequency and Mechanical Pre-stress
}

\section{Soheil Talebian $\mathrm{a}^{*}$}

${ }^{a}$ Department of Mechanical Engineering, Razi University, Kermanshah, Iran

\begin{tabular}{ll}
\hline K E Y W O R D S & A B S T R A C T \\
\cline { 1 - 2 } $\begin{array}{l}\text { Terfenol-D } \\
\text { Magnetic Hysteresis Loss }\end{array}$ & $\begin{array}{l}\text { One of the major limitations of using Terfenol-D in actuators and sensors is its magnetic } \\
\text { hysteresis power loss which leads to reduction of mechanical power loss, precision and } \\
\text { linear measuring range in actuators and sensors, respectively. In this paper, magnetic } \\
\text { hysteresis power loss of Terfenol-D and its affecting parameters are studied and modeled } \\
\text { experimentally. To this end a fabricated experimental setup is used to obtain magnetic } \\
\text { behavior of Terfenol-D consisting of major and minor hysteresis loops at different values of } \\
\text { Received: August 26, 2021 }\end{array}$ \\
frequency, magnetic field intensity and mechanical pre-stress. Data of these loops are used \\
as an input to analytical equation of magnetic hysteresis loss. The results show that the \\
magnetic hysteresis loss increases with increasing in frequency and peak value of magnetic \\
field intensity and decreasing in mechanical pre-stress. Then, an explicit model based on \\
power relations for frequency, peak value of magnetic field intensity and mechanical pre- \\
stress is presented to predict magnetic hysteresis power loss. This model is validated \\
under new different conditions and the results show very good agreement with analytical \\
model. The main advantage of the explicit model is that it does not need hysteresis loops as \\
input data and it can predict the magnetic hysteresis power loss only by determining the \\
values of conditional parameters.
\end{tabular}




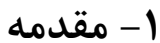

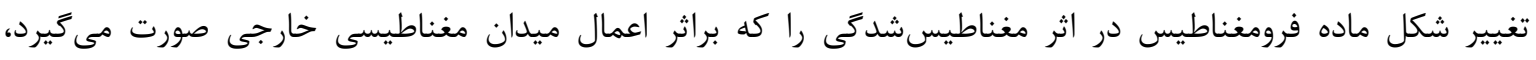

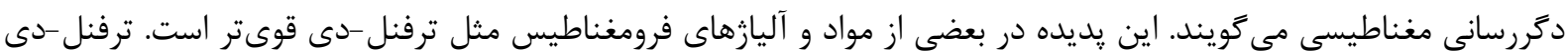

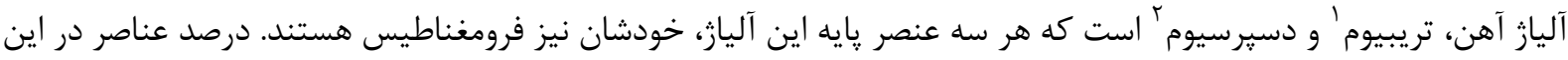

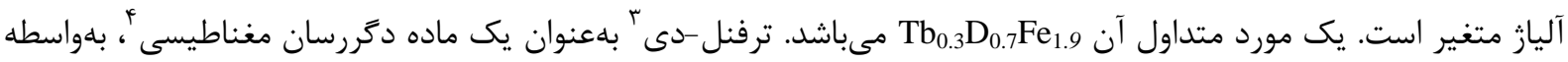

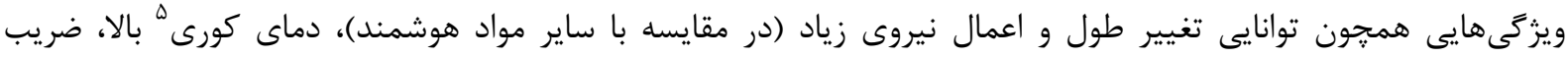
كويلينگ

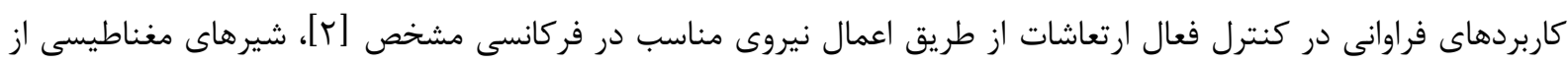

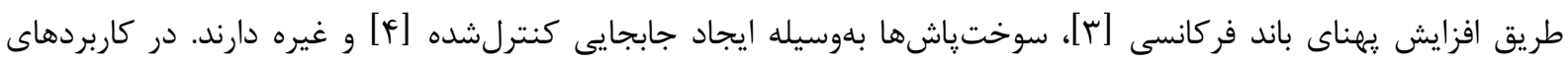

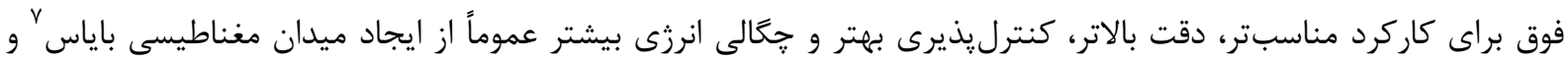

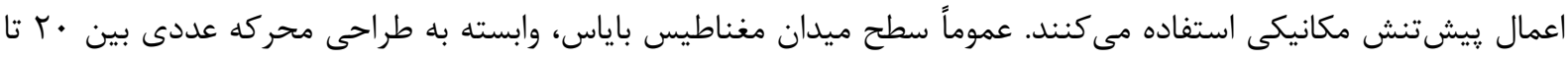

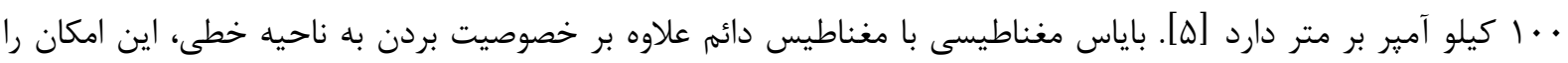

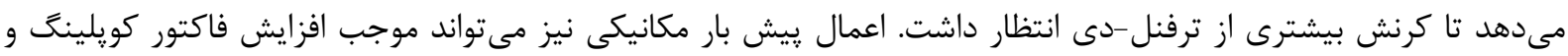
ضريب دَر رسانى مغناطيسى و بهببود عملكرد ترفنل -دى شود.

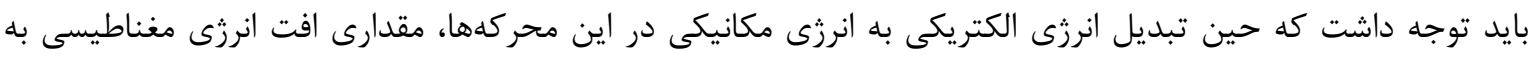

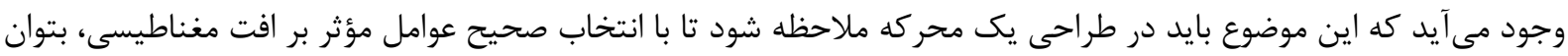

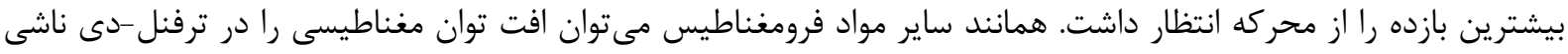

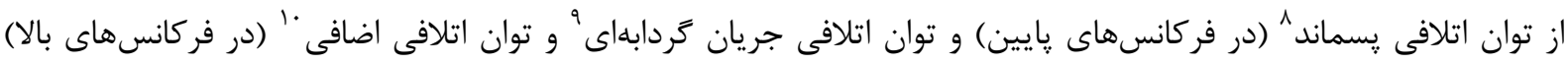

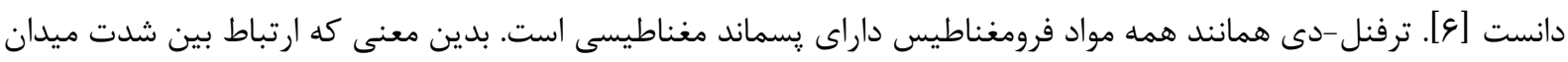

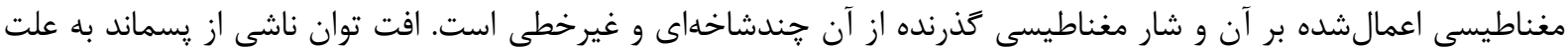

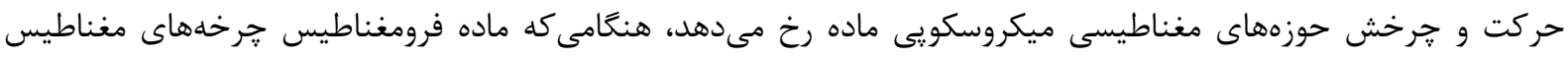

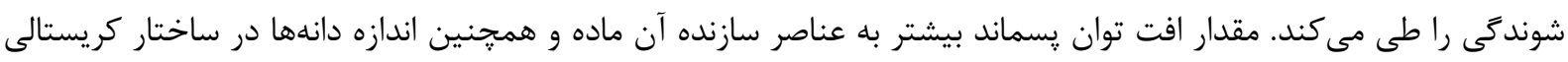

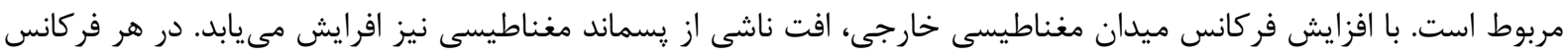

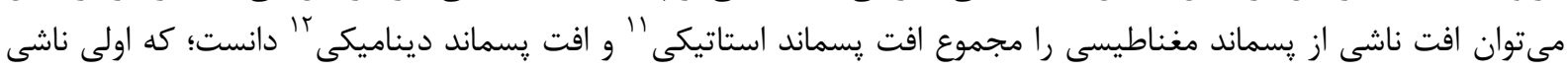

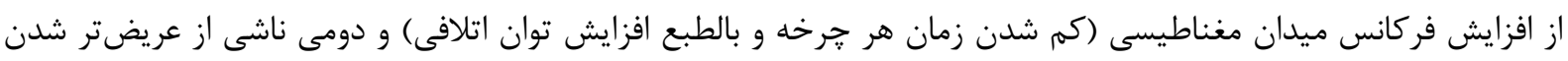

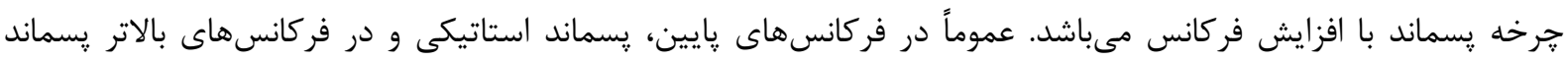

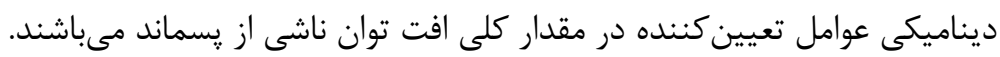

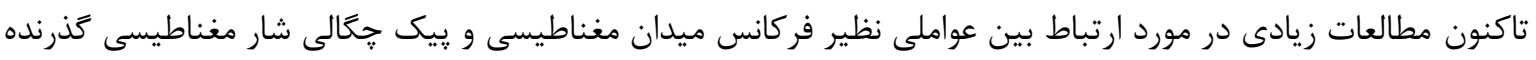

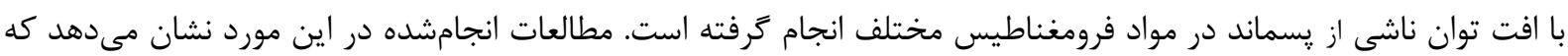

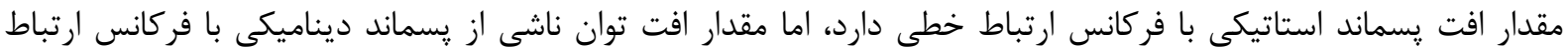

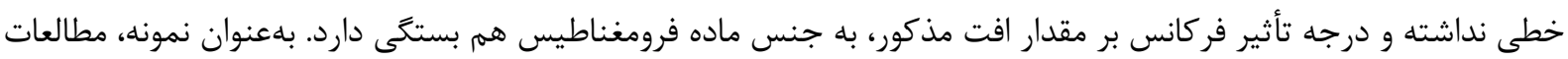

\footnotetext{
${ }^{1}$ Terbium

${ }^{2}$ Dysprosium

${ }^{3}$ Terfenol-D

${ }^{4}$ Magnetostrictive

${ }^{5}$ Curie temperature

${ }^{6}$ Coupling coefficient

${ }^{7}$ Bias

${ }^{8}$ Hysteresis power loss

${ }^{9}$ Eddy currents power loss

${ }^{10}$ Excess power loss

${ }^{11}$ Static hysteresis power loss

${ }^{12}$ Dynamic hysteresis power loss
} 
تجربى نشان مى دهند كه افت توان ناشى از پسماند ديناميكى در فيلم IV [V] Fe/Au، فيلم

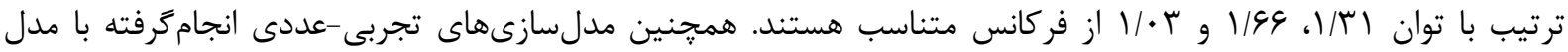

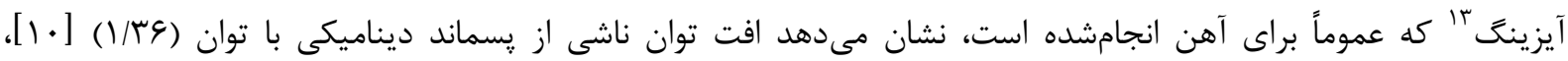

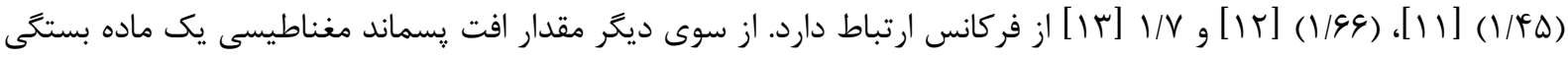

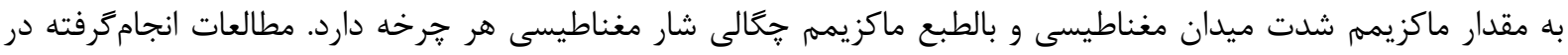

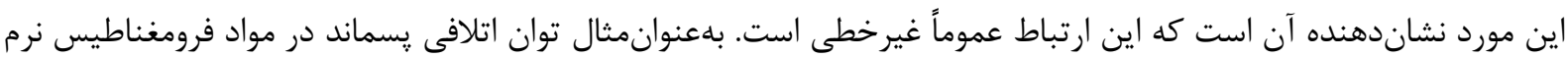

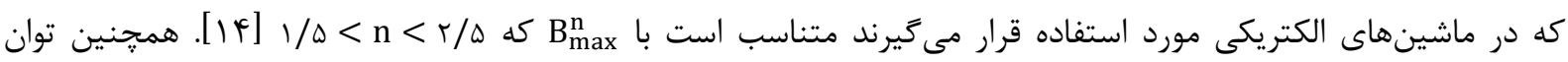
اتلافى يسماند در آهن [ها [1]، فيلم

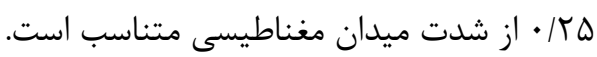

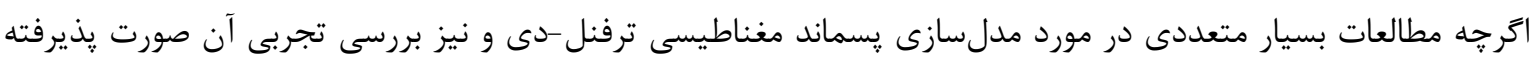

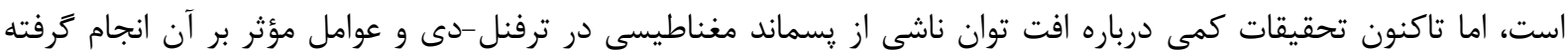

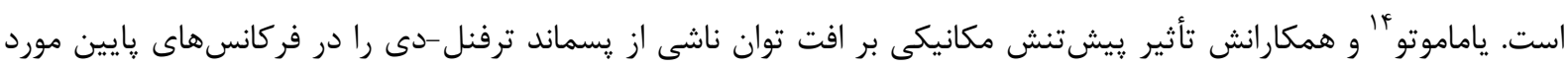

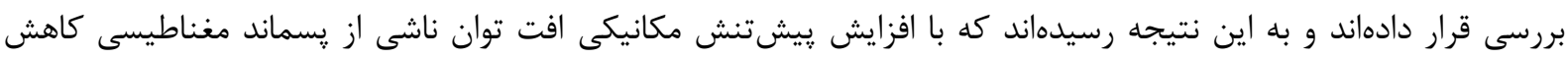

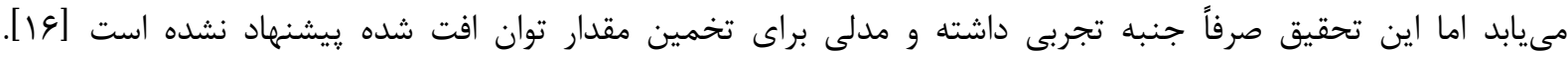

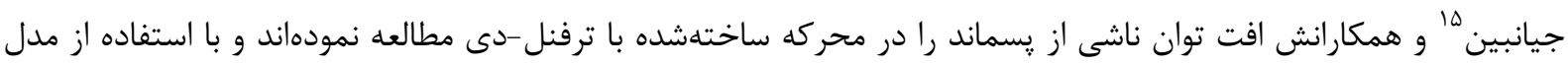

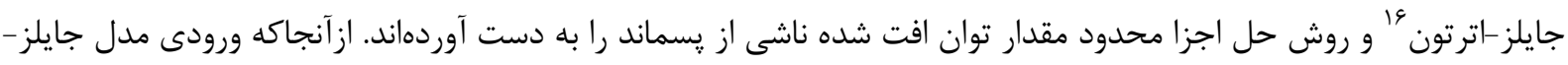

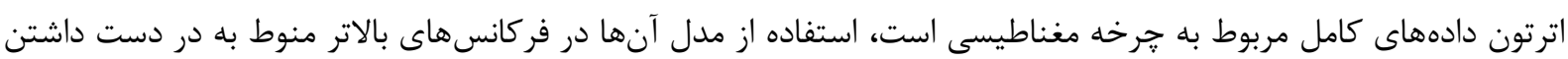

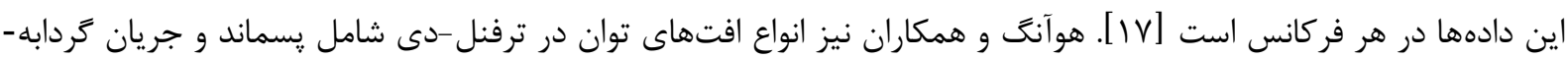

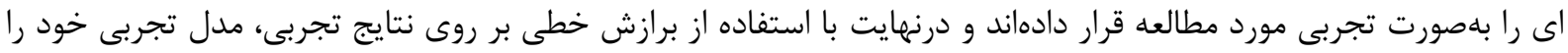

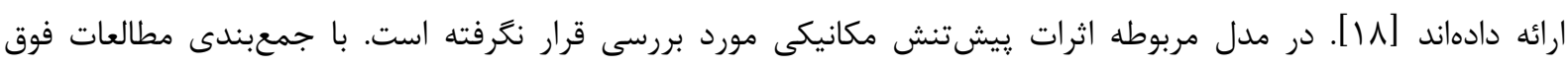

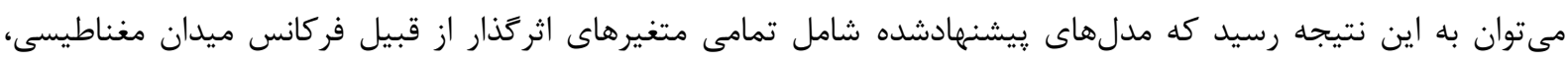

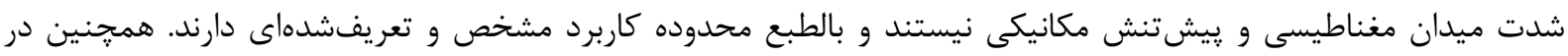

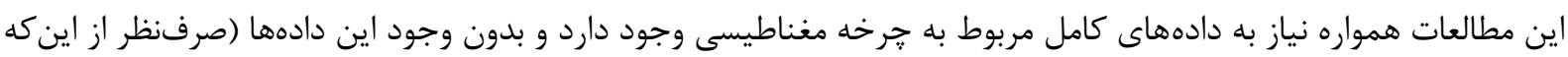

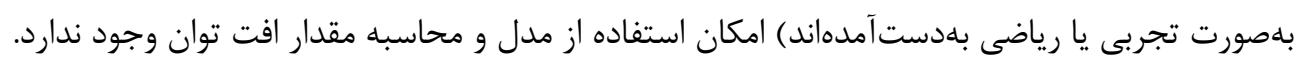

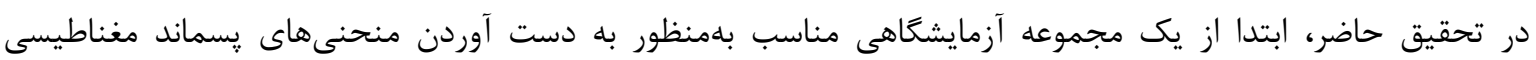

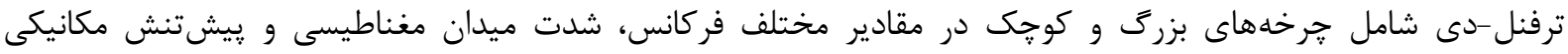

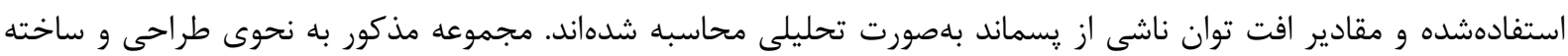

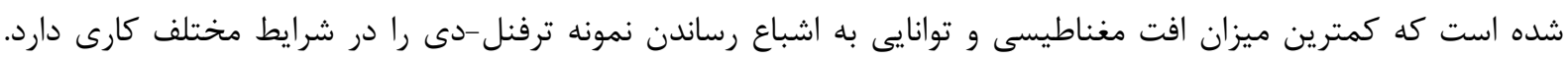

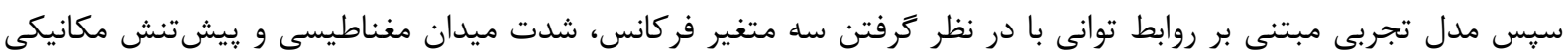

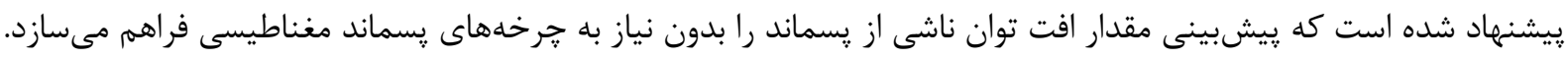

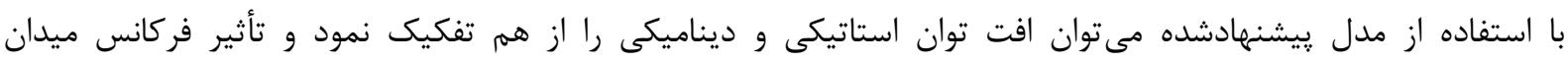

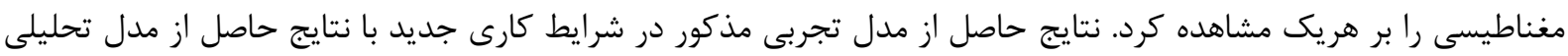

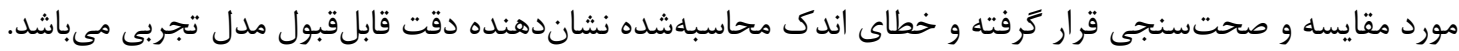

r- ( ب آزمايشهاى تجربى

هدف از انجام آزمايشهاى تجربى، مطالعه رفتار مغناطيسى ترفنل-دى از طريق به دست آوردن منحنىهاى پٍماند آن

\footnotetext{
${ }^{13}$ Ising model

${ }^{14}$ Yamamoto

15 Jianbin

${ }^{16}$ Jiles Atherton
}

مكانيك مواد بِيشرفته و هوشمند / سال ••f/ دوره // شماره | 


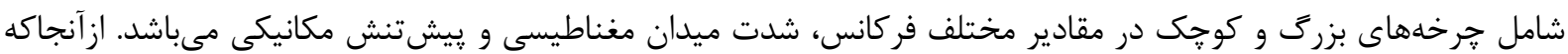

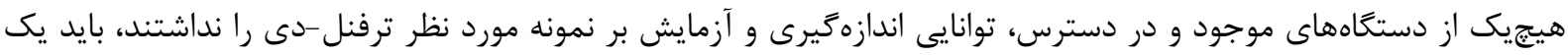

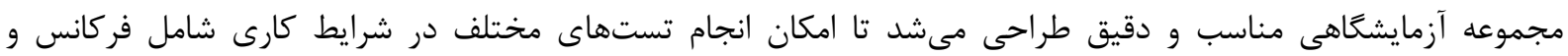

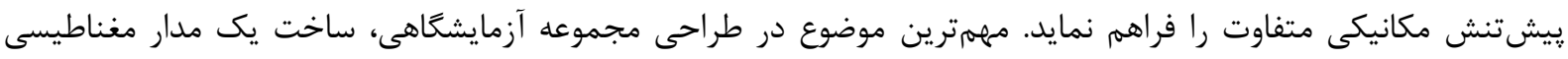

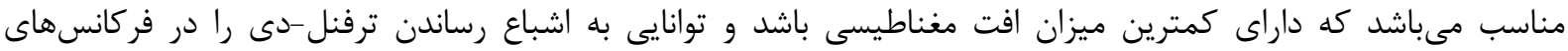

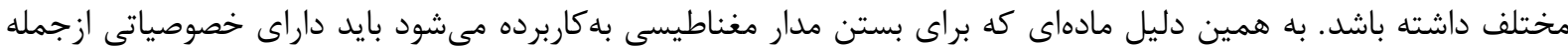

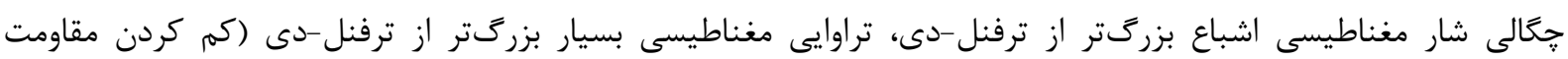

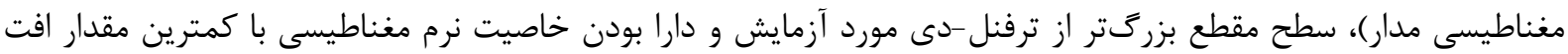

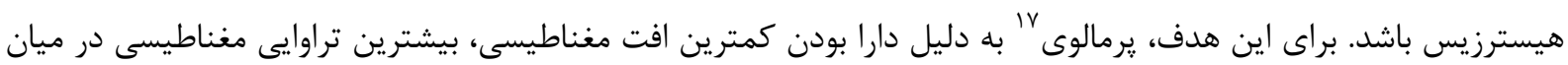

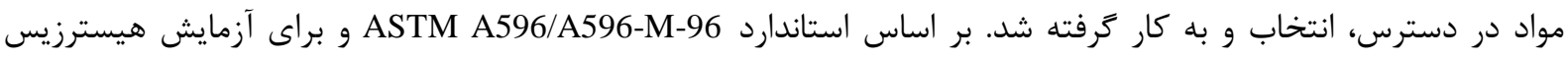

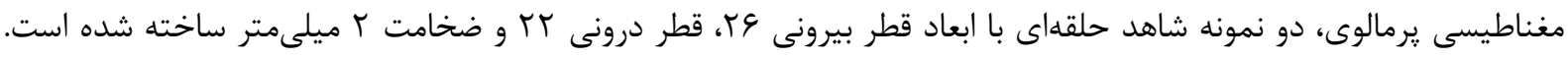

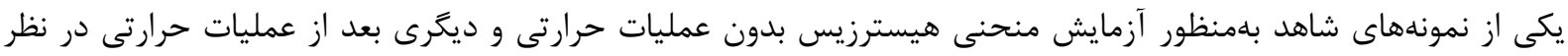

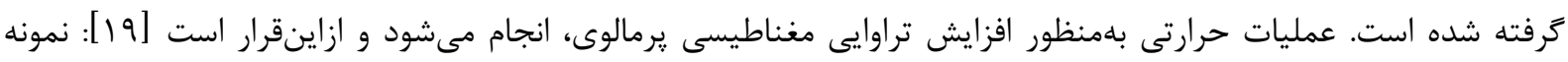

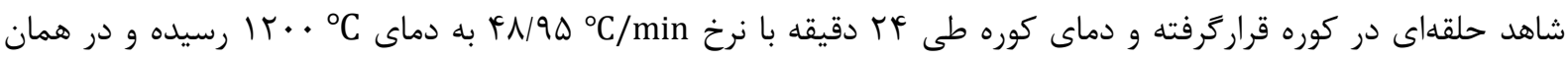

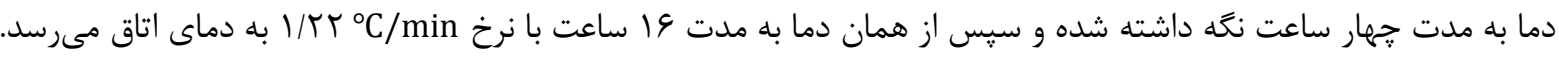
شماتيك آزمايش منحنى هيسترزيس مغناطيسى در شكل ا نشان داده شده است. نمونه شاهد حلقهاى به دو سيمييج

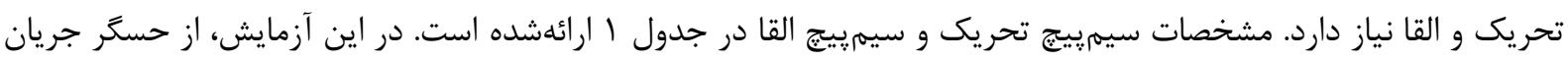

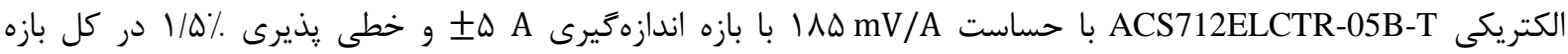

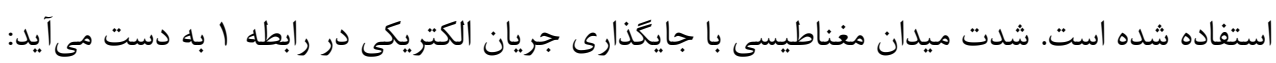
$H=N I / L$

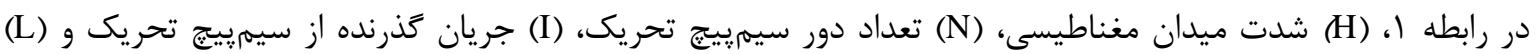

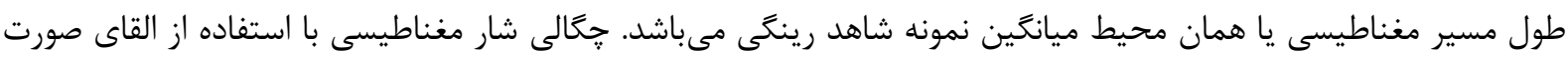
كرفته در سيمييج القا و طبق قانون القاى فارادى اندازمخيرى مئىشود:

$V=-N \frac{d \emptyset}{d t}=-N A \frac{d B}{d t}$

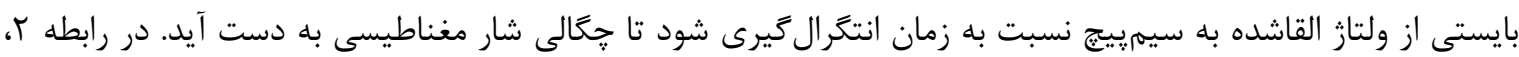

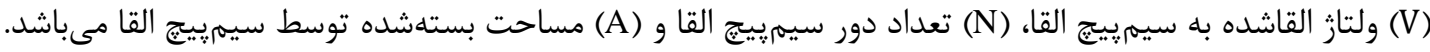

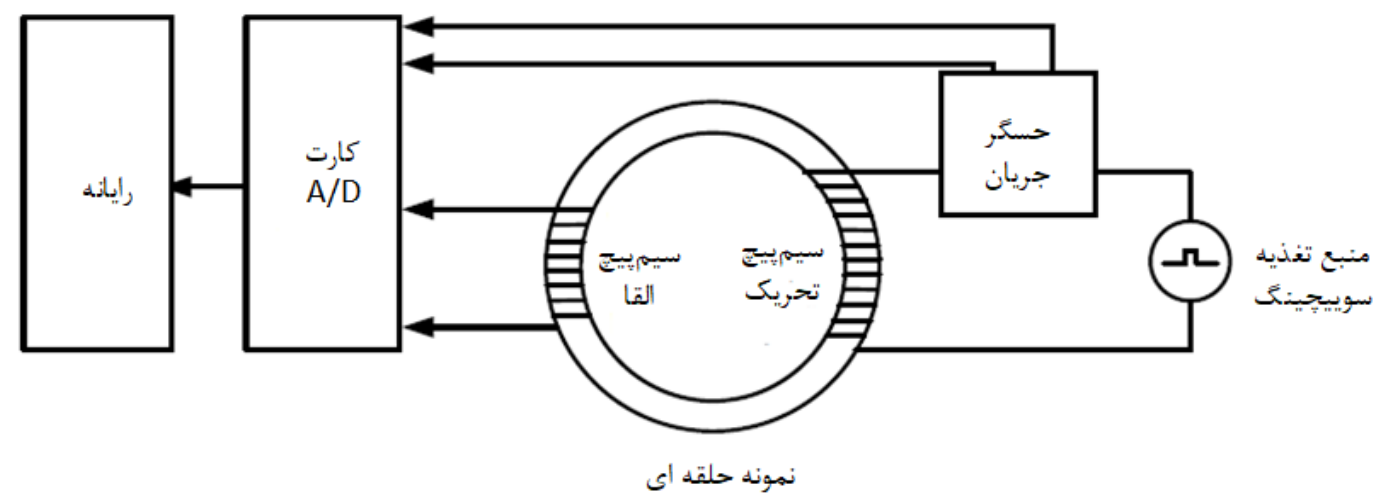

شكل ا شماتيك مجموعه آزمايشعاهى اندازهخيرى يسماند يرمالوى

\footnotetext{
${ }^{17}$ Permalloy
} 
جدول ا مشخصات سيم ييج تحريك و سيميبيج القا

\begin{tabular}{|c|c|c|}
\hline لاكى به قطر \& / • ميلىمتر & تعداد دور & سيمييج تحريك \\
\hline 1. & تعداد دور & \\
\hline لاكى به قطر ض|/ • ميلى متر & نوع سيم & سيمر يِيج القا \\
\hline F/D ميلىمتر مربع & مساحت بستهشده & \\
\hline
\end{tabular}

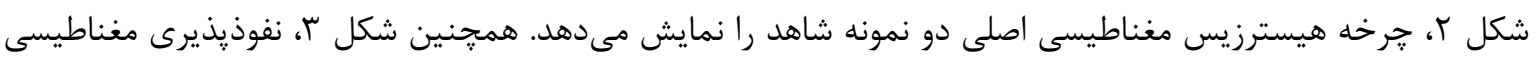

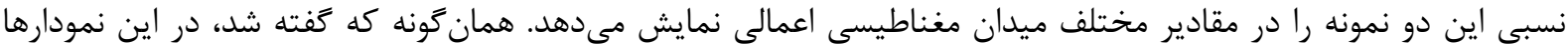

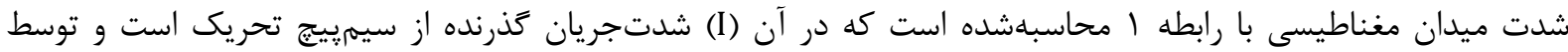

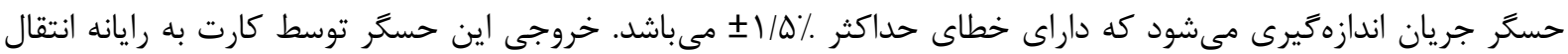

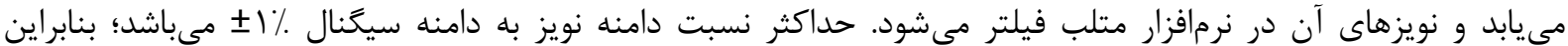

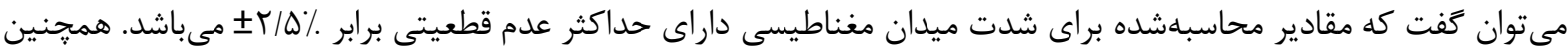

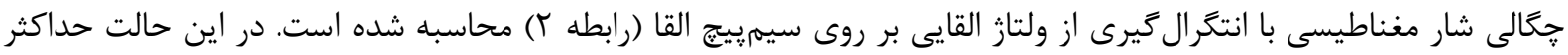

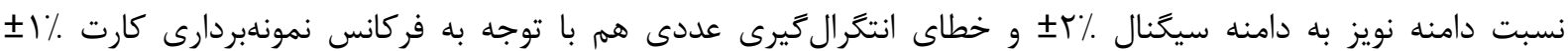

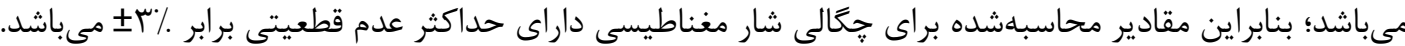
با توجه به اين دو نمودار، مشاهده مىشود كه پِ از عمليات حرارتى يرمالوى، بهناى خرخه هيسترزيس كاهش و

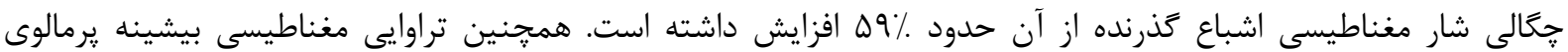

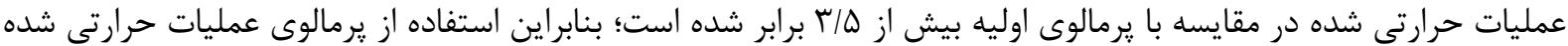

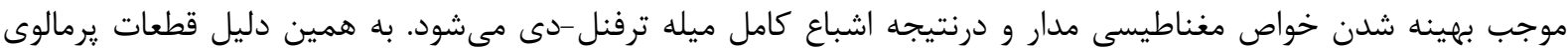
بهكار فته در مجموعه آزمايشكاهى خواص مغناطيسى ترفنل-دى همخًى عمليات حرارتى شدهاند.

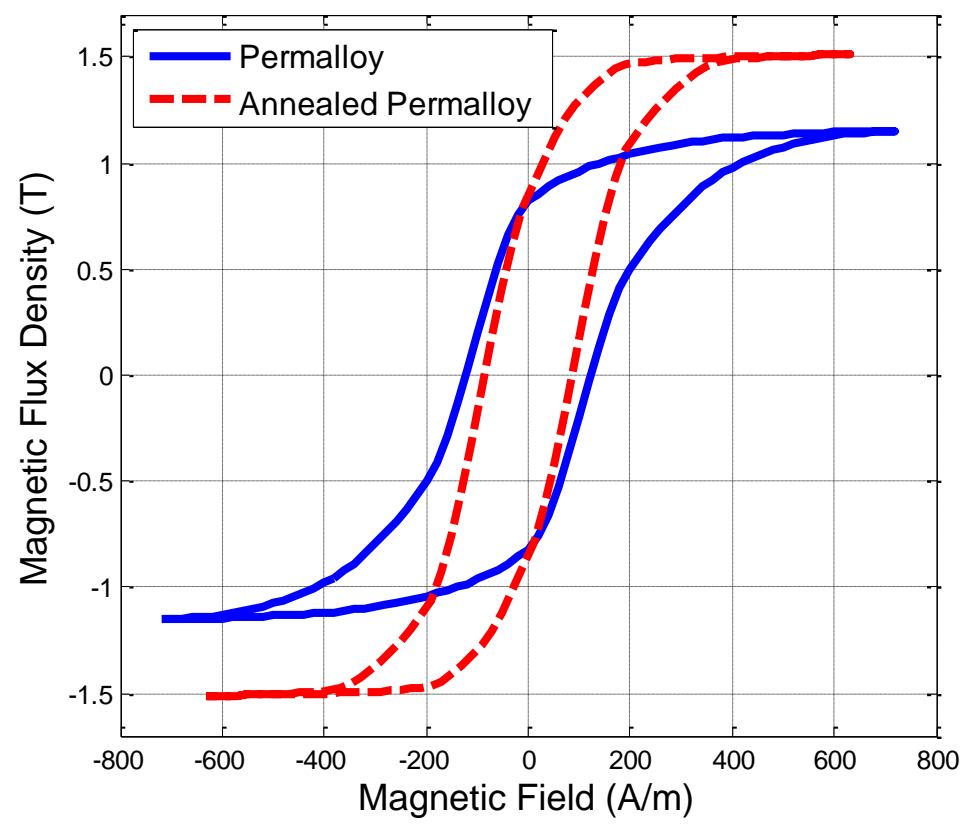

شكل r جرخههاى يسماند بزرت يرمالوى 


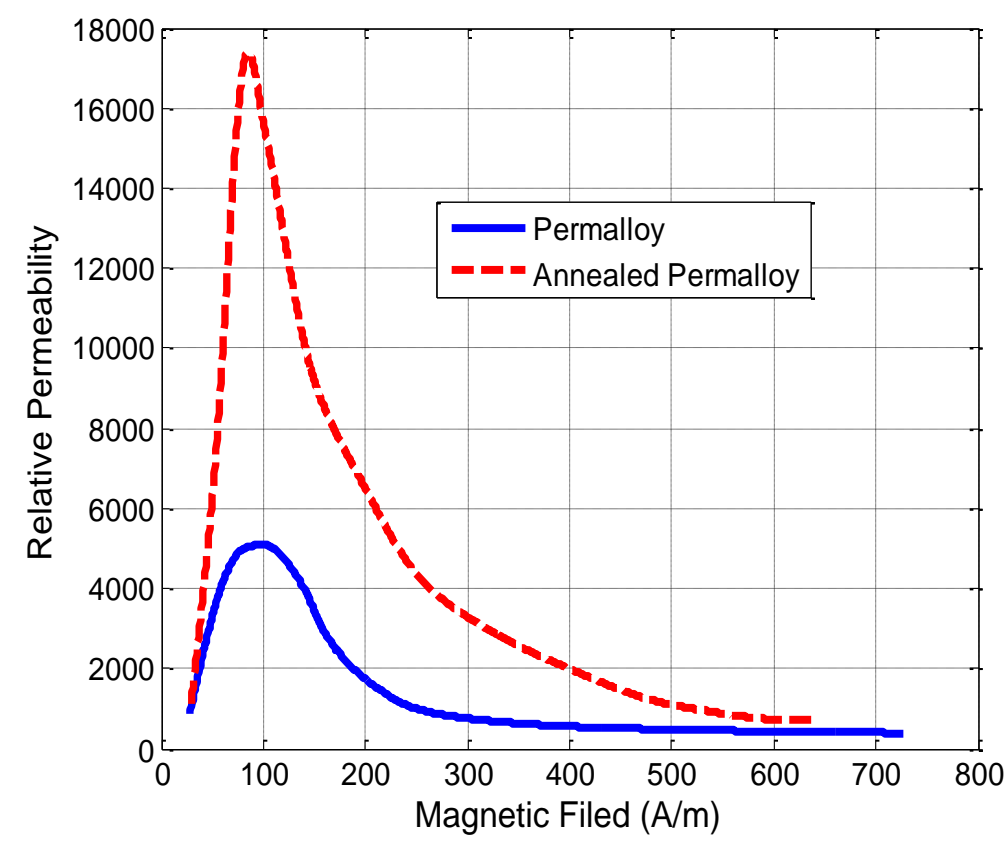

شكل ץ نفوذيذيرى مغناطيسى برمالوى در ميدان هاى مغناطيسى مختلف

r-1- إمجموعه آزمايشعاهى بر رسى يسماند مغناطيسى ترفنل -دى

از مدار مغناطيسى ساختهشده با يرمالوى بهمنظور به دست آوردن منحنىهـاى يسـماند مغناطيسى ترفنـلــى در شـرايط

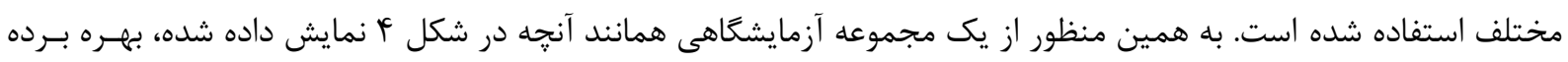
شده است.

اين مجموعه آزمايشكاهى علاوه بر مدار مغناطيسى ساختهشده، داراى اجزاى زير نيز مىباشند:

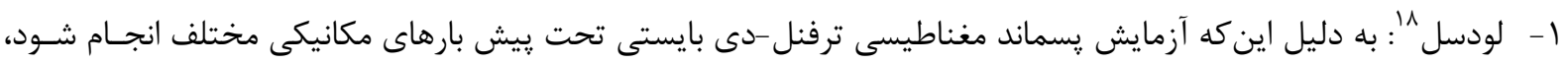

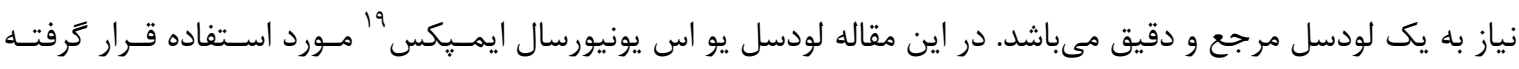

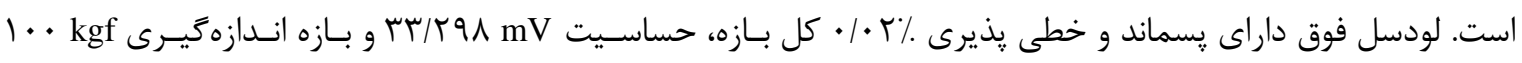
مىباشد. ז- منبع تغذيه Gwinstek APA-9201) AC): اين منبع قادر به توليد ولتاز سينوسى تا فركانس · له هرتز و توان ا كيلووات مىباشد.

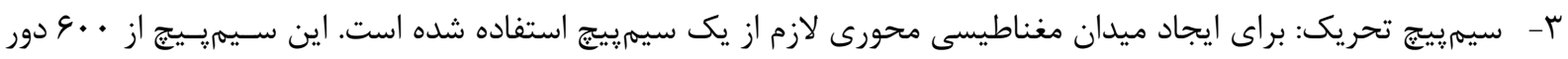

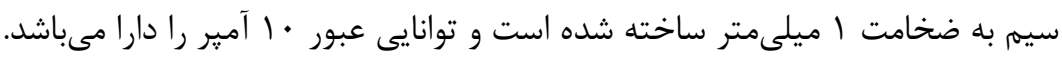

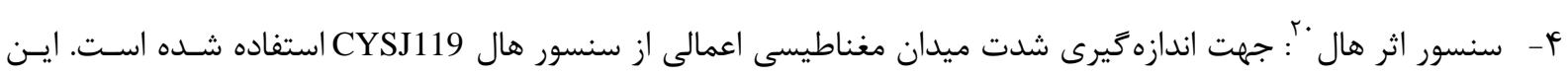

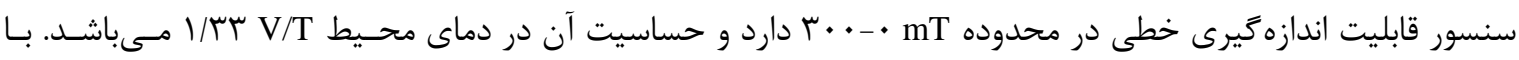

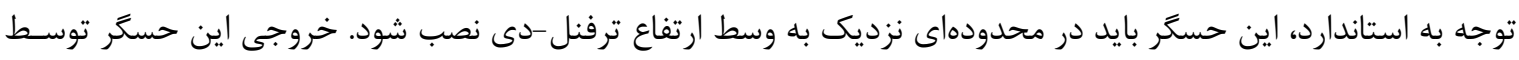

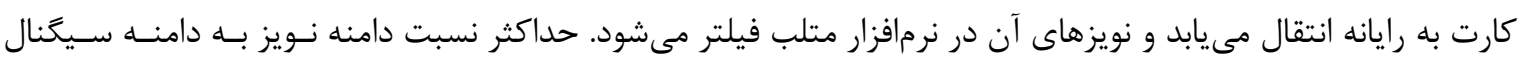
.

\footnotetext{
${ }^{18}$ Loadcell

${ }^{19}$ US Universal Impex

${ }^{20}$ Hall effect sensor
} 


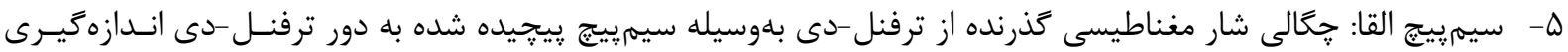

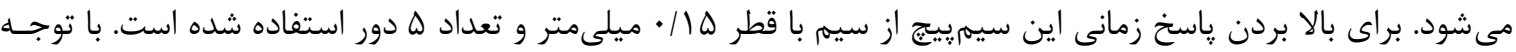

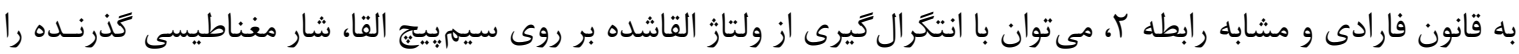
محاسبه نمود.

9- كارت A/D: براى ارسال سيكنالهاى خروجى سيمييج القاو سنسور هال به كامِيوتر از كارت A/D استفاده شده است.

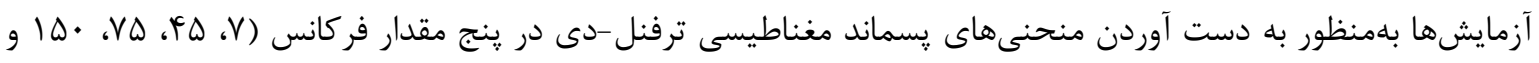

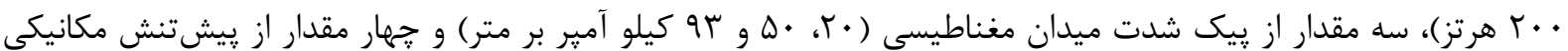

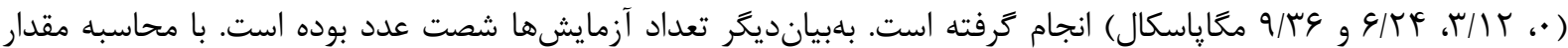

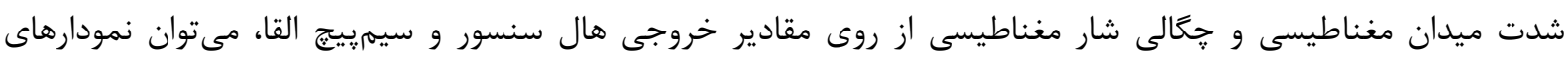

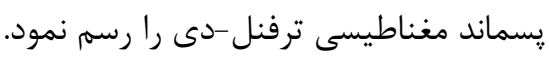

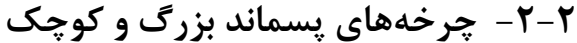

نمودارهاى نشان داده شده در شكل ه خرخههاى بزرى يسماند مغناطيسى ترفنل-دى را در ينج فر كانس مختلف و در

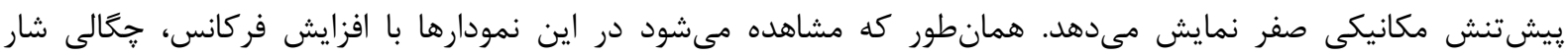
مغناطيسى كذرنده از ترفنل-دى به ازاى يكى مقدار مشخص از شدت ميدان مفان مغناطيسى كاهش مى يابد. همجنين نمودارها

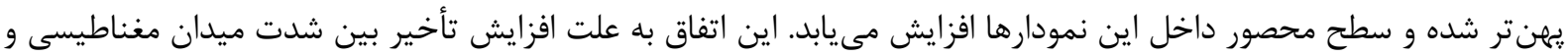

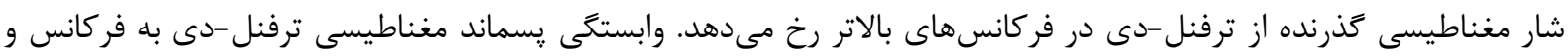

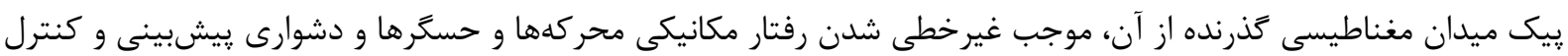

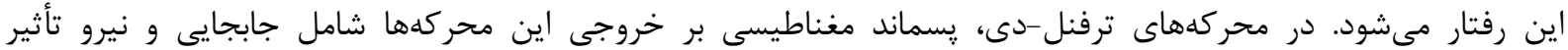

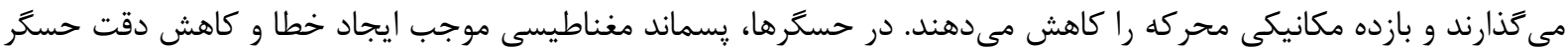

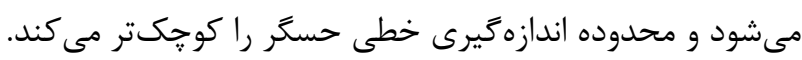

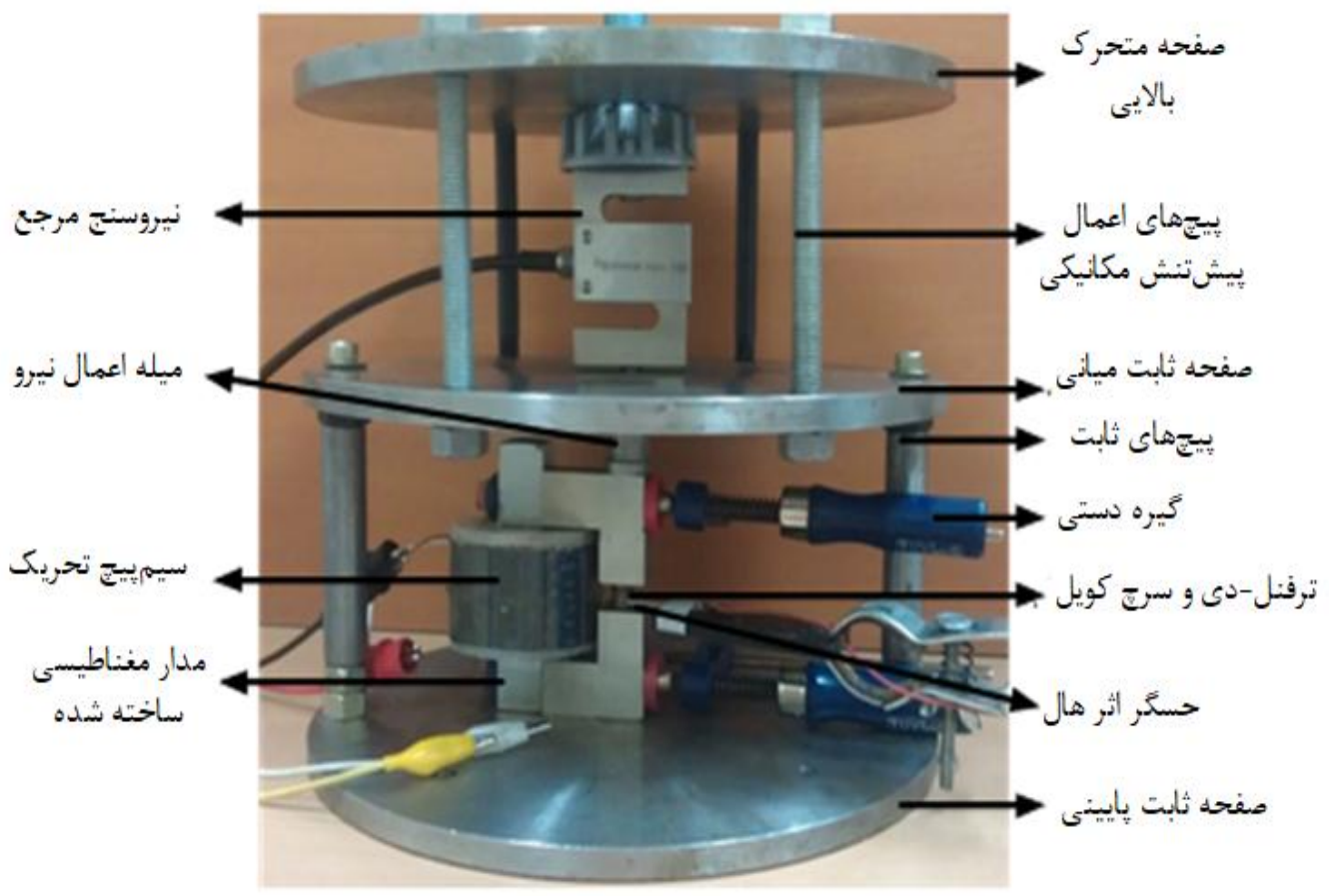

شكل f مجموعه آزمايشًَاهى جهت مطالعه يسماند مغناطيسى ترفنل -دى

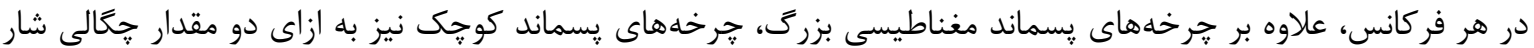




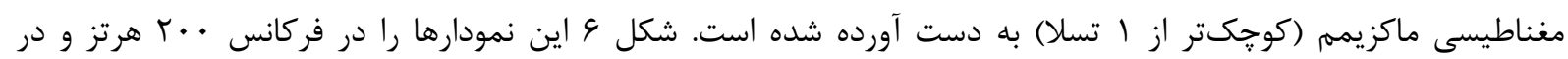
ييشتنش مكانيكى صفر نمايش مىدهد.

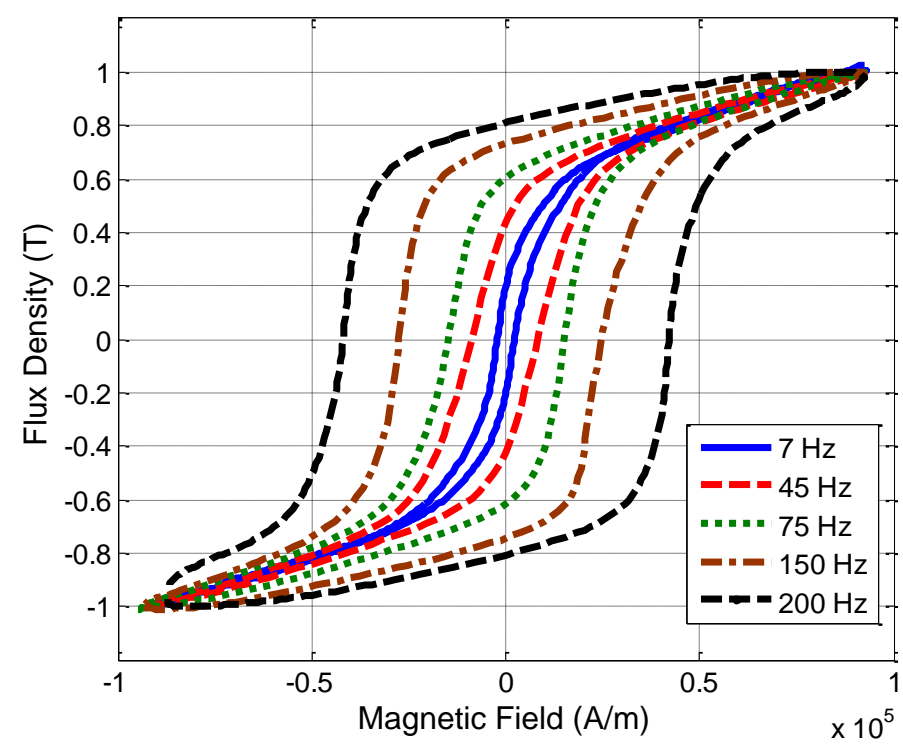

شكل ه هرخه هاى يسماند بزرى ترفنل-دى در فركانسهاى مختلف و پِيش تنش مكانيكى صفر

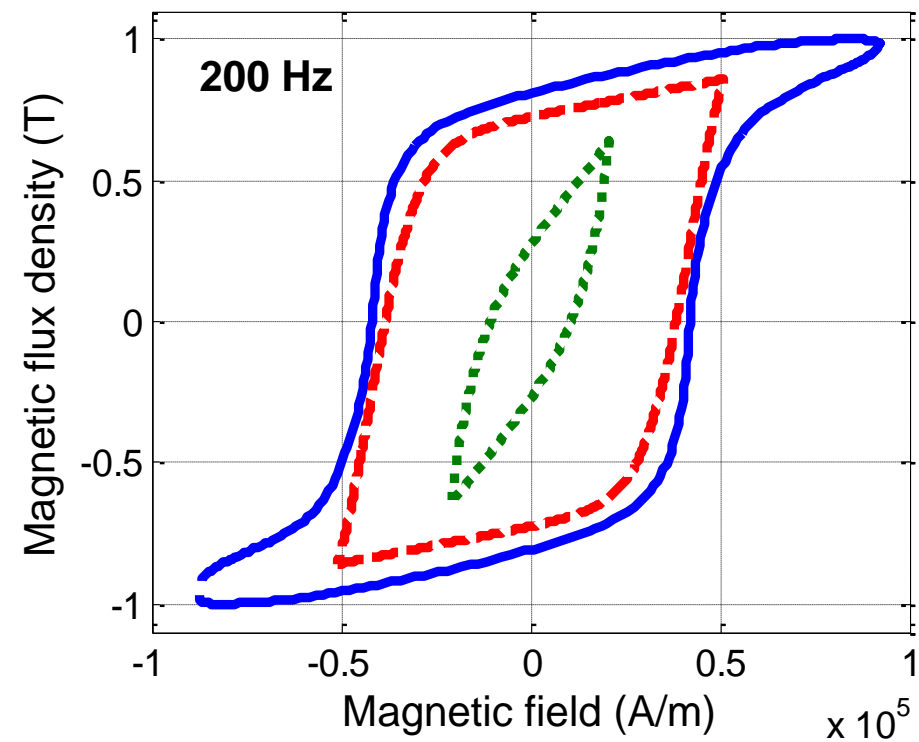

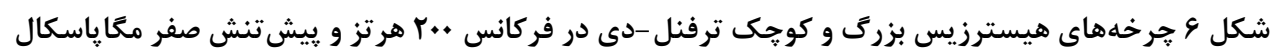

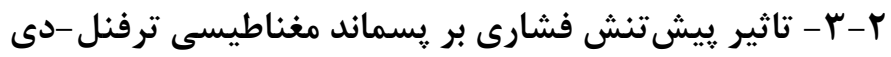

تأثير اعمال يیشتنش فشارى بر منحنىهاى يسماند ترفنل-دى در شكلهاى ل و ^ نشان داده شده است. در اين نمودارها،

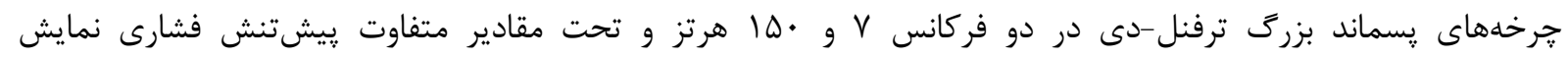

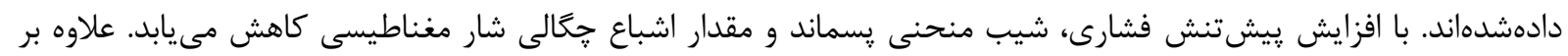

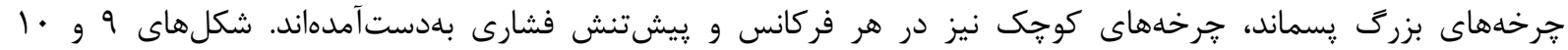

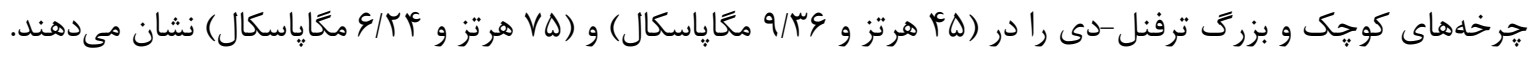




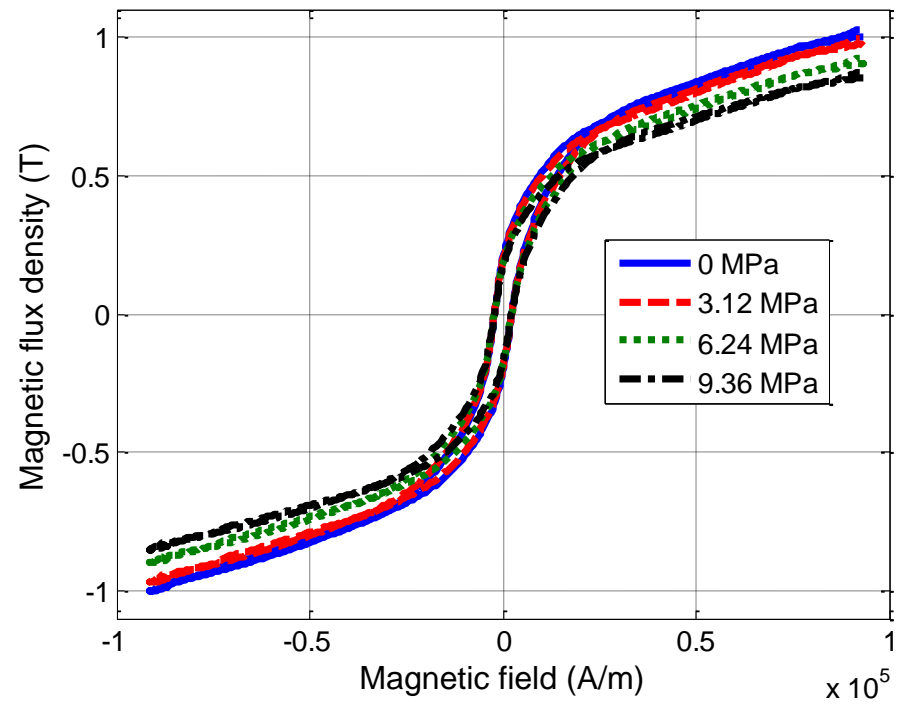

شكل V. جرخههاى بزرى يسماند ترفنل -دى در فركانس V هرتز به ازاى مقادير مختلف يِيشتنش مكانيكى

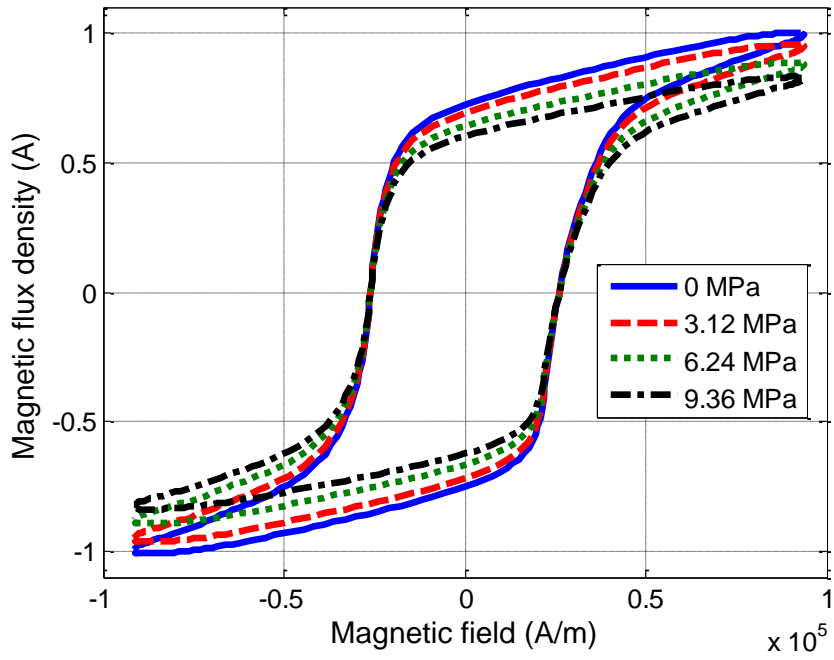

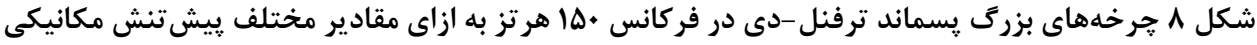

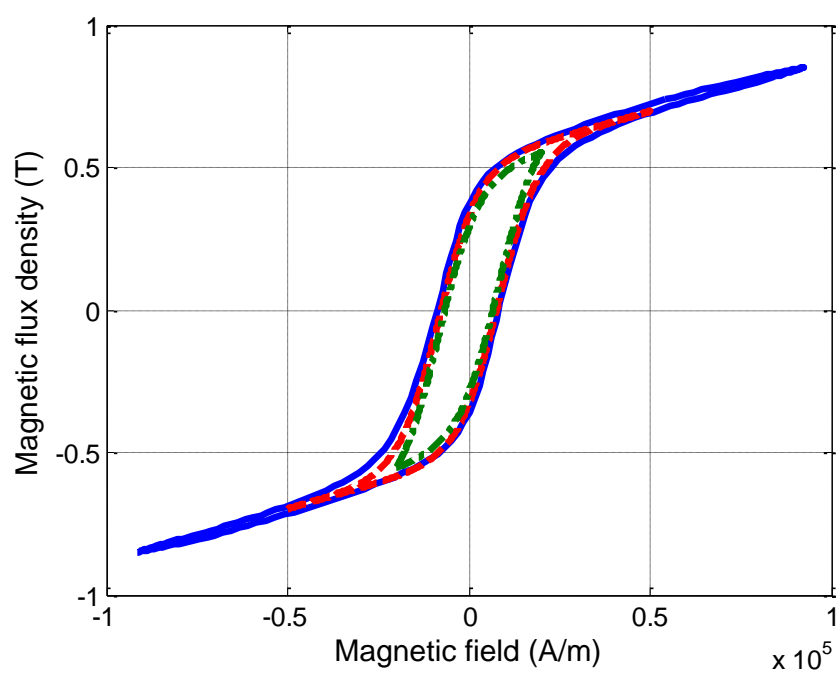

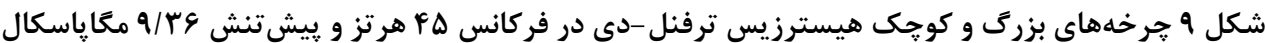




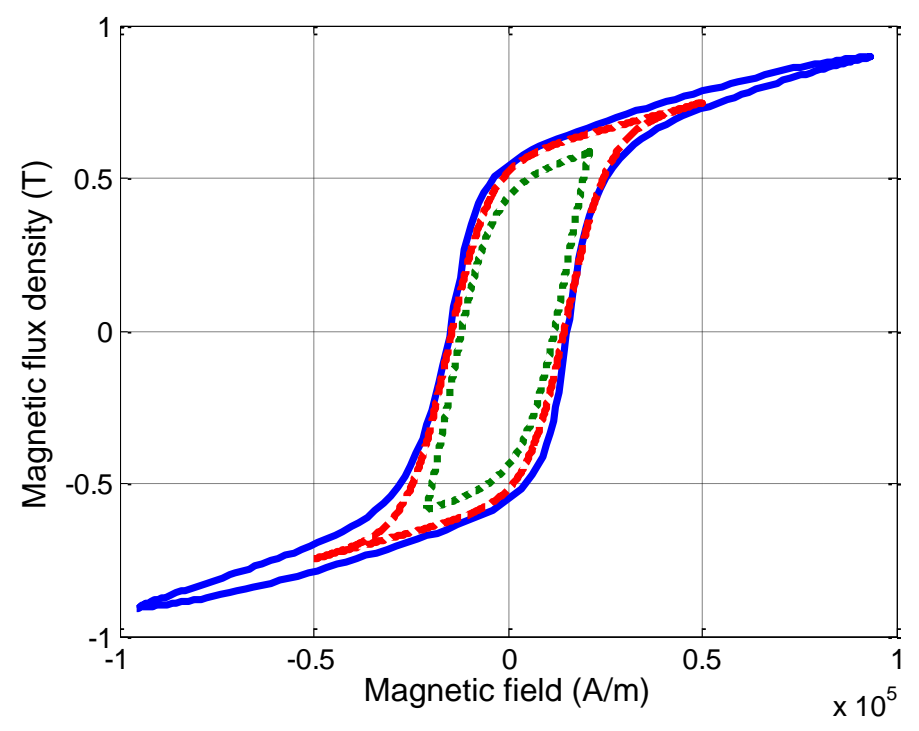

شكل •l هرخهاى بزرى و كوجك هيسترزيس ترفنل -دى در فركانس VD هرتز و يِشتنش

r- (1) n

مساحت محصورشده توسط نمودار B-H در هر فر كانس نشاندهنده انرزى اتلافى ناشى از يسماند در واحد حجم ماده

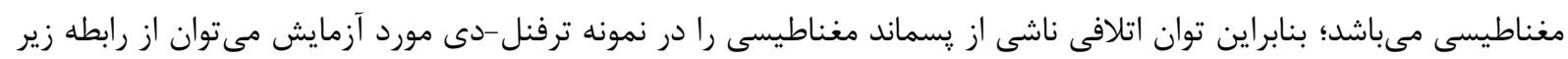
$P_{\text {hys }}=V f \int H \cdot d B$

در اين رابطه V حجم نمونه مورد آزمايش و f فركانس ميدان مغناطيسى است. با استفاده از رابطه سَ، افت توان يسماند در

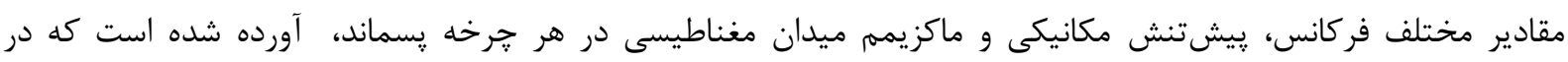

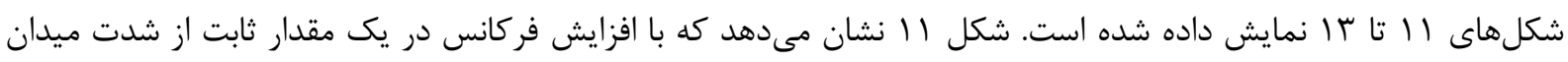

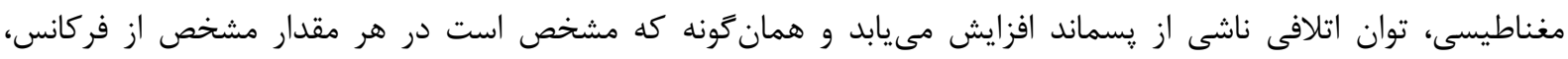

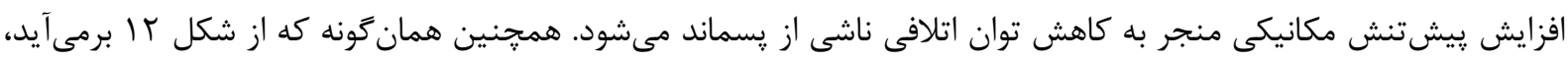

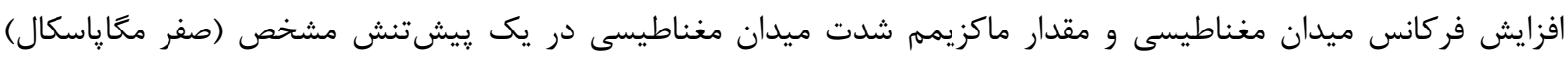

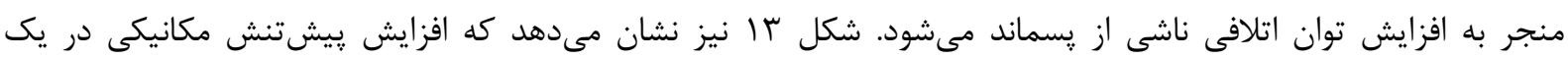

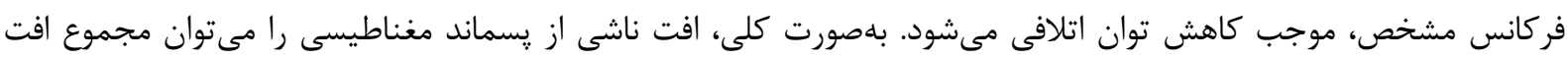

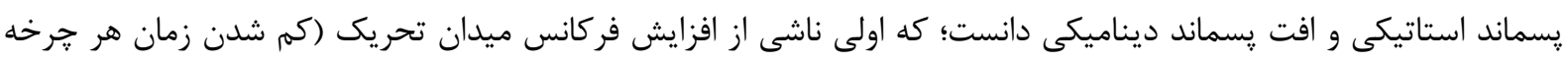

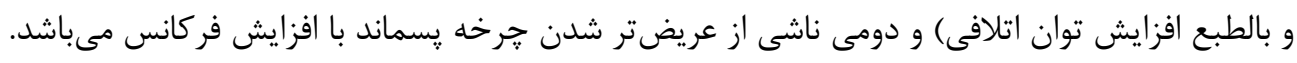

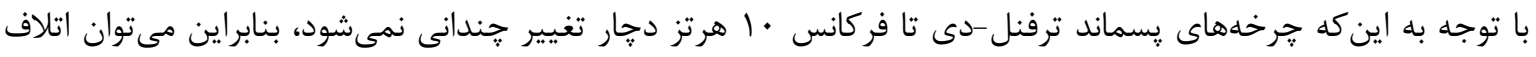

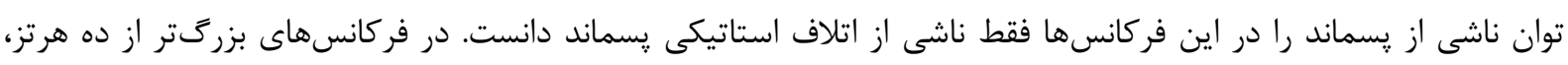

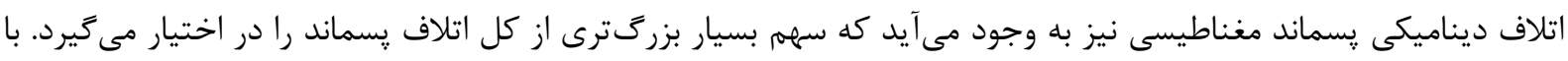

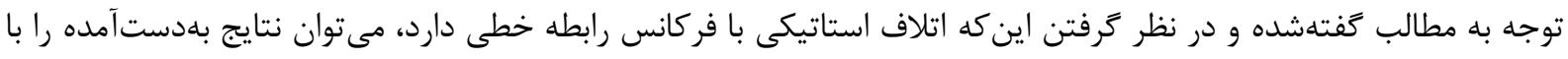

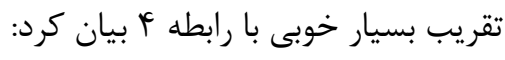

$$
\begin{aligned}
& P_{\text {hys }}=P_{\text {static }}+P_{\text {dynamic }} \\
& =(20.131) f^{1.031} H_{p}^{1.331} P^{-0.0696}+(0.2235) f^{2.264} H_{p}^{1.317} P^{-0.0687} \mathrm{~W} / \mathrm{m}^{3}
\end{aligned}
$$




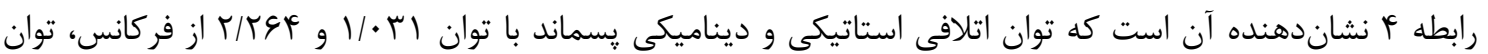

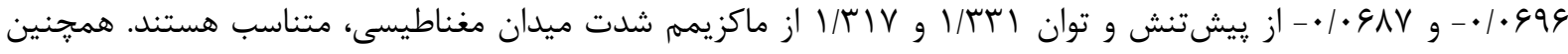
مىتوان توان اتلاف كلى را بلهورت مستقيم بلصورت تابعى از فركانس، ييشتنش و ماكزيمم شدت ميدان مغناطيسى بيان

با مقايسه دو رابطه fأ و له مى توان دريافت كه افت كلى يُماند عمدتاً ناشى از افت ديناميكى پسماند مىباشد، جراكه توان

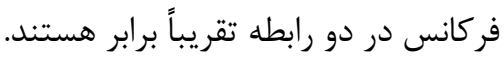

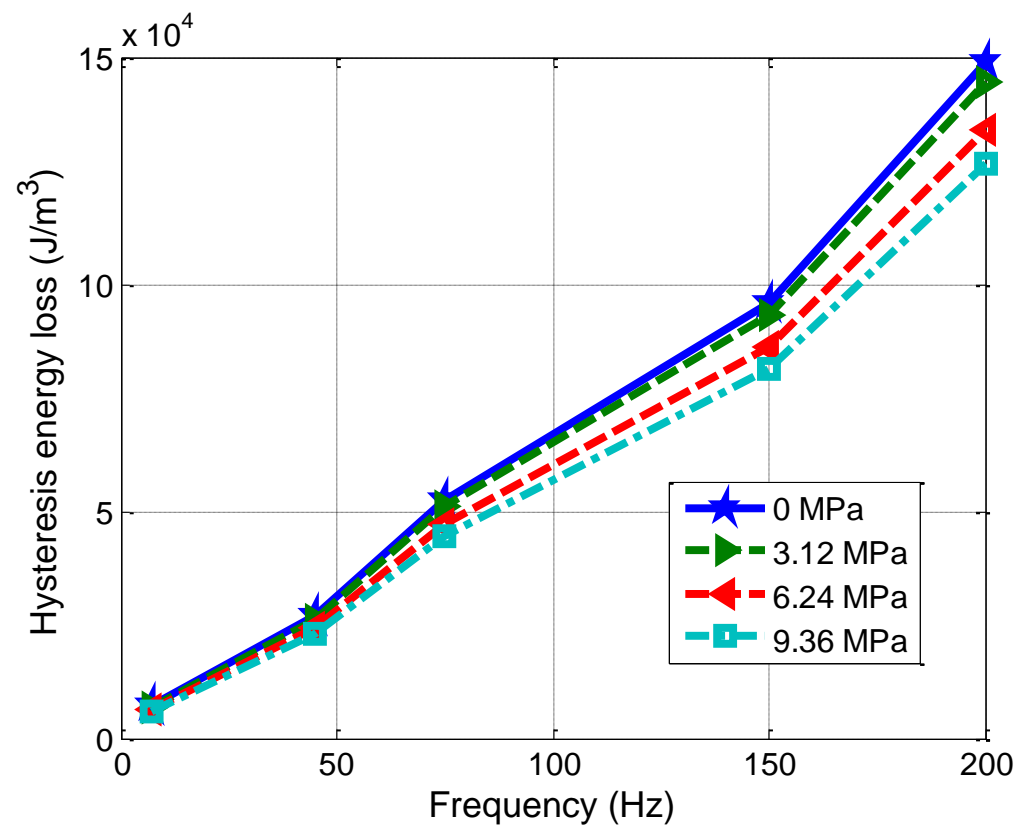

شكل ال إحكالى انرزى اتلافى هيسترزيس به ازاى فركانس در شدت ميدان مغناطيسى سو كيلوآمير بر متر

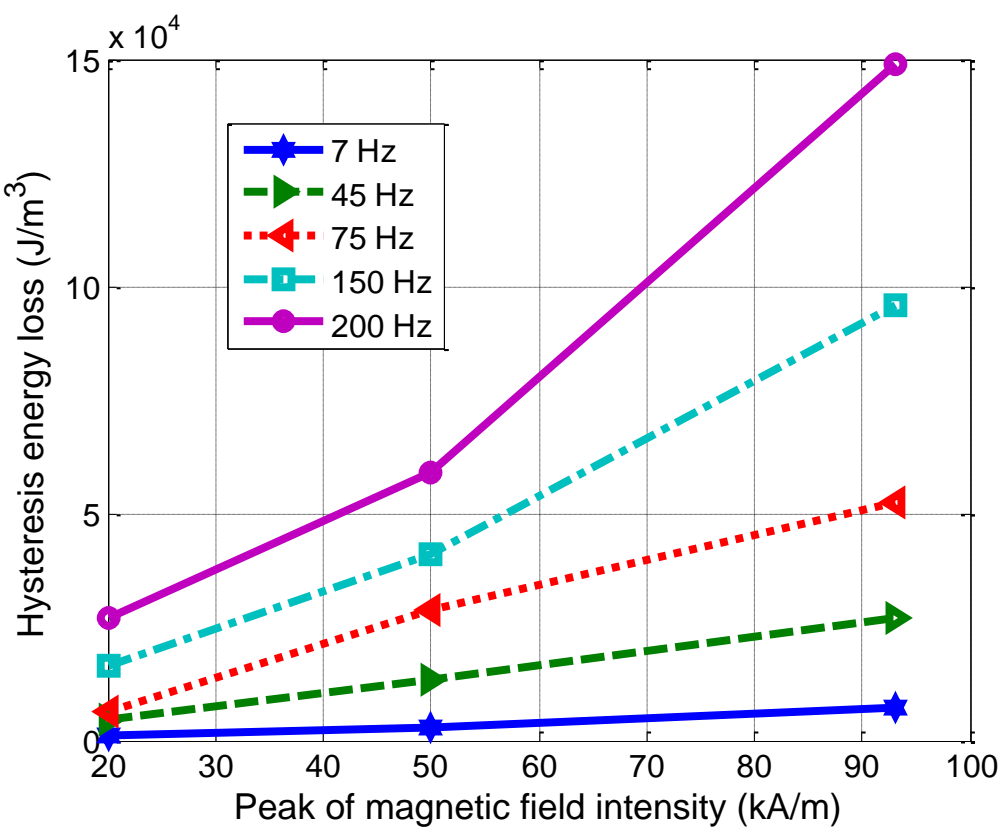

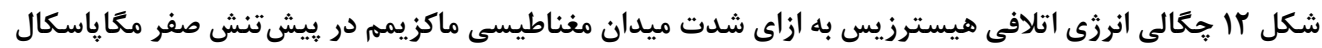




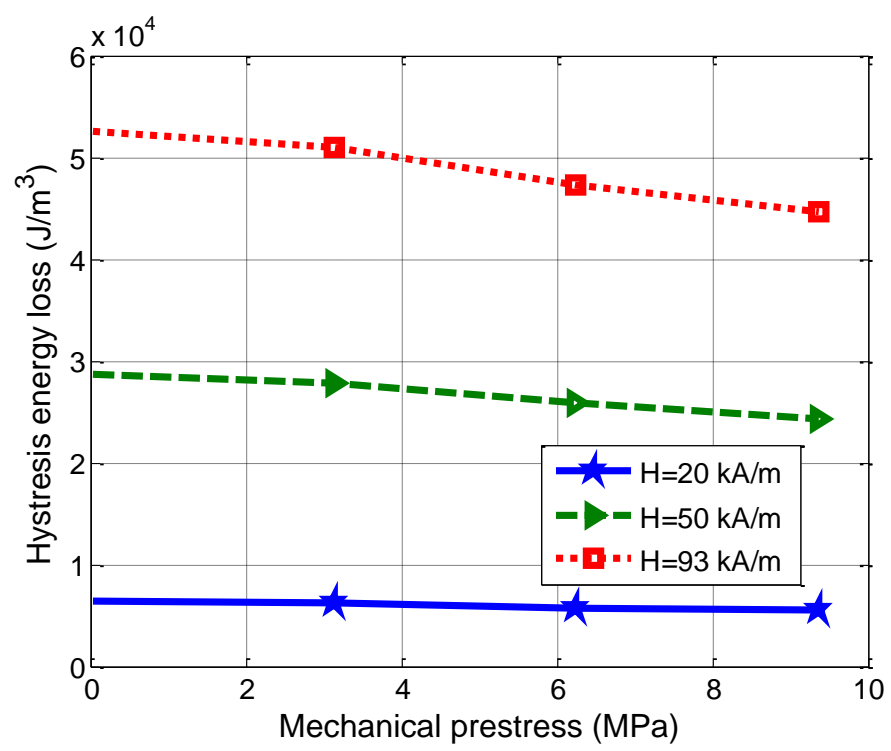

شكل سا جحكالى انرزى اتلافى هيسترزيس به ازاى پيشتنش فشارى در فركانس VD هرتز

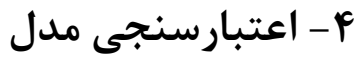

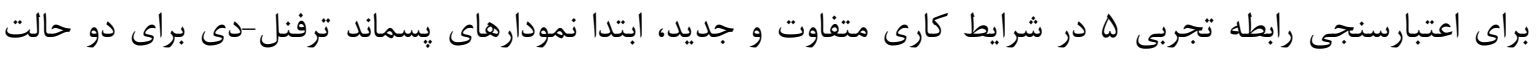

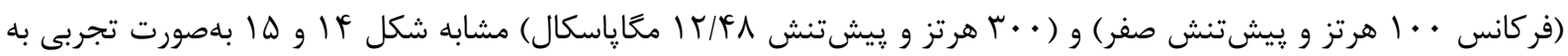

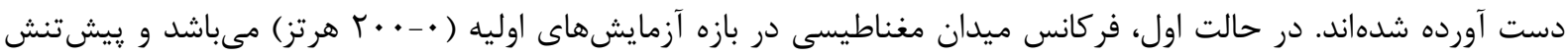

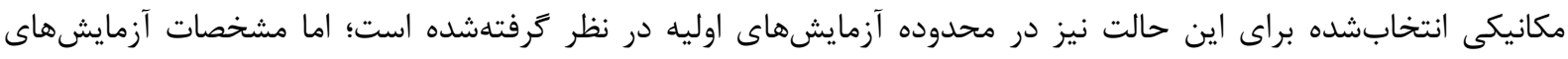

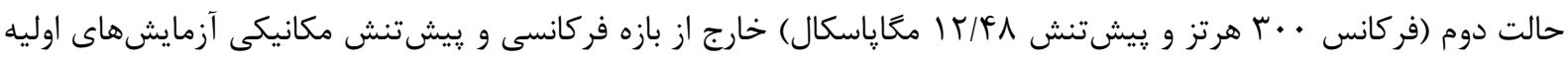

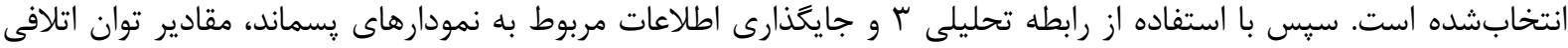

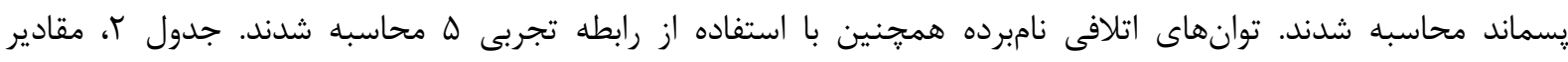

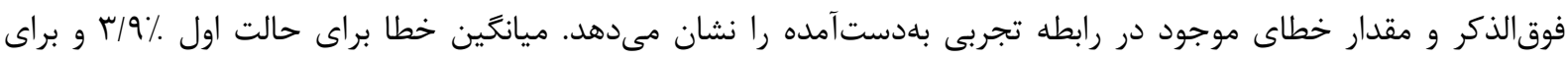
حالت دوم ه. مىباشد.

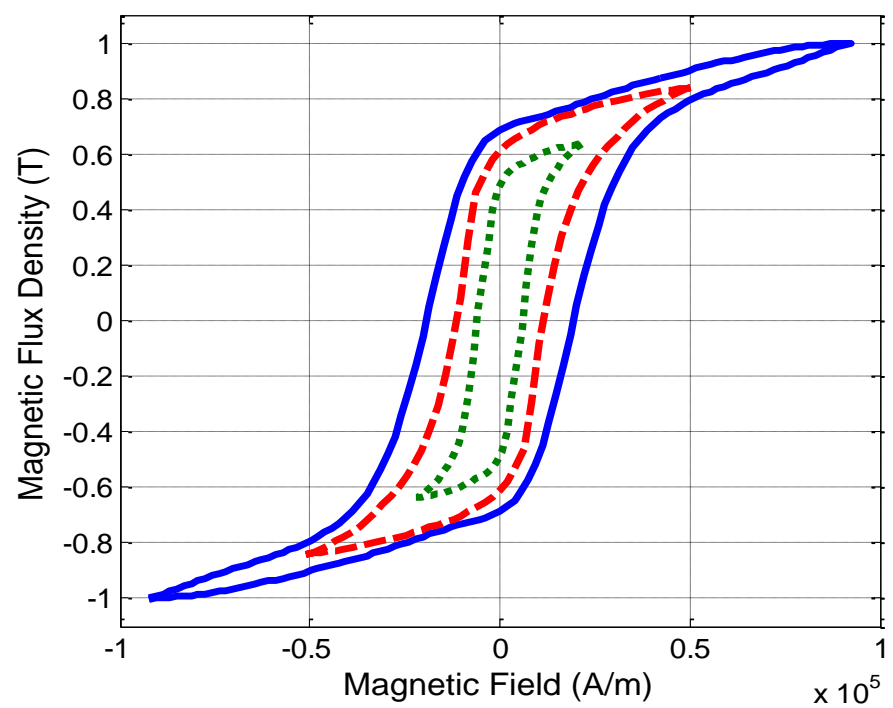

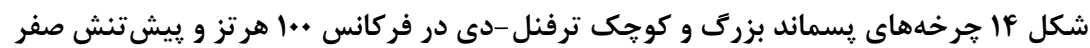




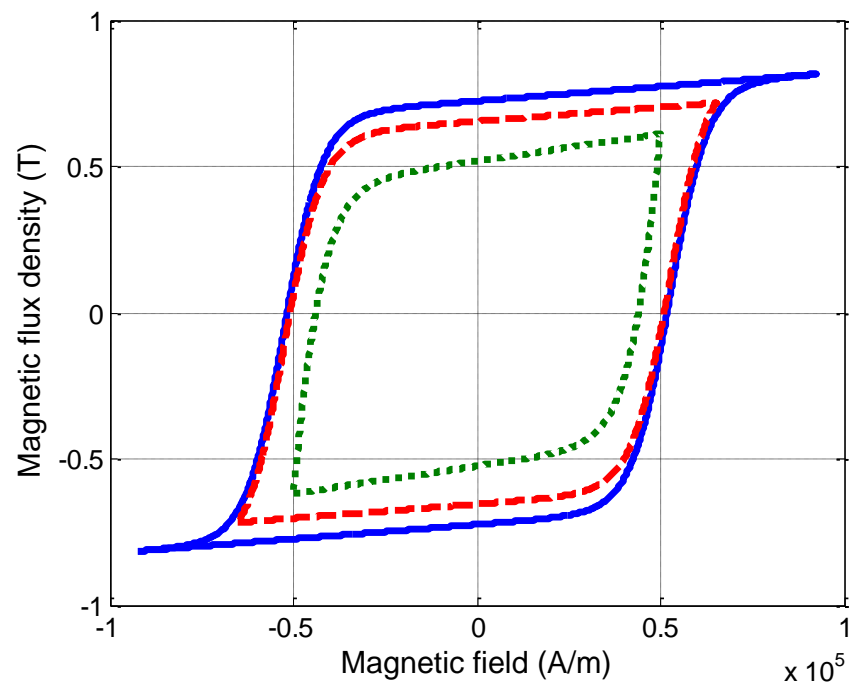

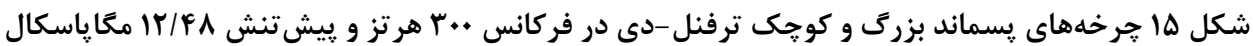

جدول ب نتايج تحليلى و تجربى توان اتلافى يسماند مغناطيسى ترفنل -دى

توان اتلافى پِماند (وات)

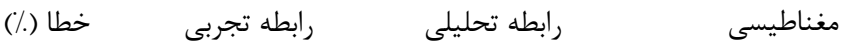

\begin{tabular}{|c|c|c|c|c|}
\hline$F / T$ & $|/| \Delta \mid$ & $1 / r \cdot r$ & TI & \multirow{3}{*}{ فركانس · · ا هرتز و ييشتنش صفر } \\
\hline$\pi / 1$ & $r / r \Delta q$ & |r/ral & $\Delta$. & \\
\hline$F / \Delta$ & $9 / 910$ & $\left.q|q|\right|^{f}$ & Tा & \\
\hline $\mathrm{V} / \mathrm{I}$ & $\Gamma \mid r \Delta \phi$ & Tr/VAl & $\Delta$. & \multirow{3}{*}{ 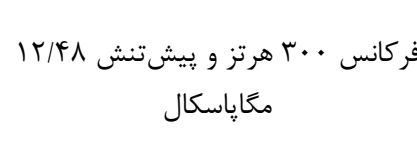 } \\
\hline$r / T$ & $F Y / T \Delta \Delta$ & Fr/^९Q & 90 & \\
\hline$F / \Lambda$ & $\checkmark \cdot / \Lambda \mu \Lambda$ & $G V / G \mid f$ & r & \\
\hline
\end{tabular}

ه ن

در مقاله حاضر، افت ناشى از يسماند مغناطيسى در ماده دخر رسان مغناطيسى ترفنل-دى مورد مطالعه تجربى و مدل سازى

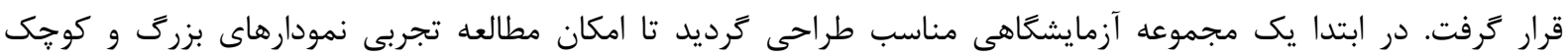

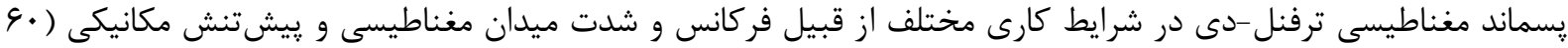

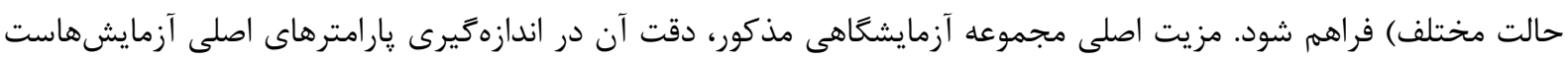

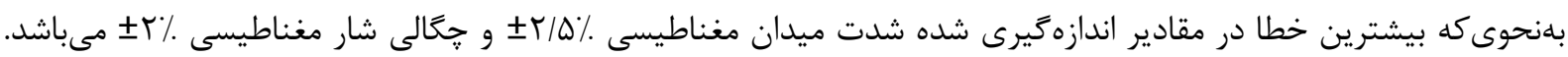

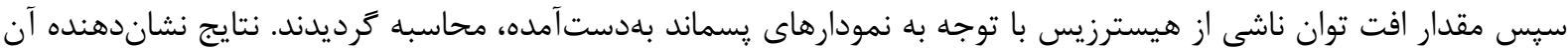

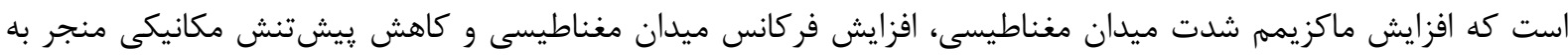

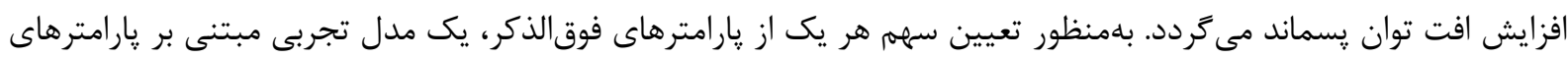

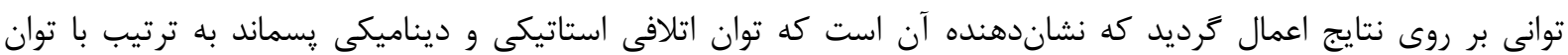

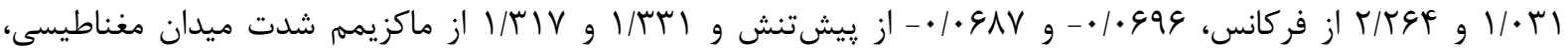

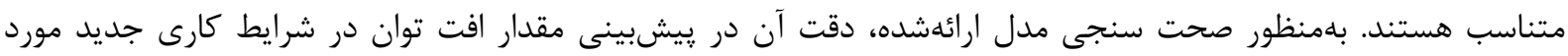

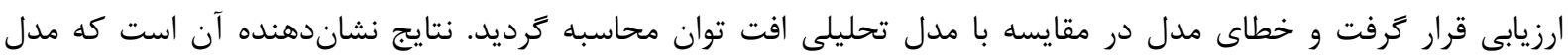

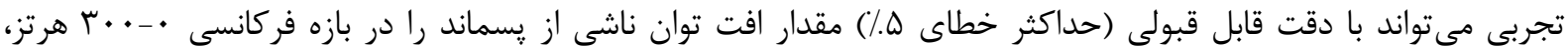

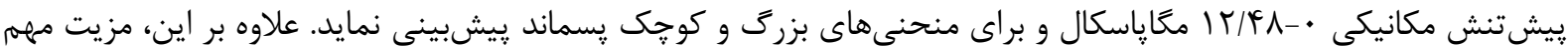

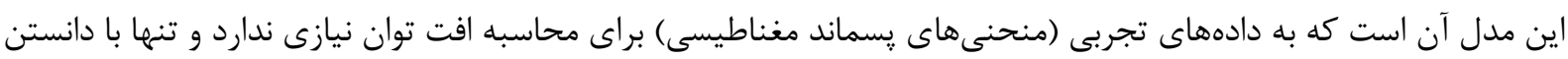

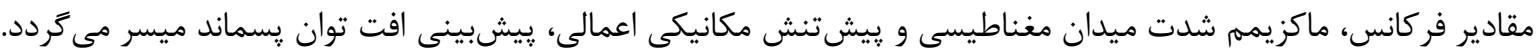




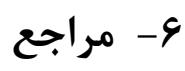

[1] Bhattacharya B. Terfenol and Galfenols: Smart magnetostrictive metals for intelligent transduction. Dir Mag (Indian Inst od Technol Kanpur). 2005;7:35-40.

[2] Goodfriend M J, Shoop K M. Adaptive characteristics of the magnetostrictive alloy, Terfenol-D, for active vibration control. Journal of intelligent material systems and structures. 1992;3:245-254.

[3] Karunanidhi S, Singaperumal M. Design, analysis and simulation of magnetostrictive actuator and its application to high dynamic servo valve. Sensors and Actuators A: Physical. 2010;157:185-197.

[4] Ghodsi M, Hosseinzadeh N, Özer A, Dizaj H R, Hojjat Y, Varzeghani N G, Sheykholeslami M R, Talebian S, Ghodsi M H, Al-Yahmadi A. Development of gasoline direct injector using giant magnetostrictive materials. IEEE Transactions on Industry Applications. 2016;53:521-529.

[5] Kellogg R A, Flatau A B. Blocked force investigation of a Terfenol-D transducer. In 1999 Symposium on Smart Structures and Materials. 1999;3668;184-195.

[6] Bertotti G. General properties of power losses in soft ferromagnetic materials. IEEE Transactions on magnetics. 1988;24:621-630.

[7] He Y L, Wang G C. Observation of dynamic scaling of magnetic hysteresis in ultrathin ferromagnetic Fe/Au (001) films. Physical review letters. 1993;70:2336-2339.

[8] Jiang Q, Yang H N, Wang G C. Scaling and dynamics of low-frequency hysteresis loops in ultrathin Co films on a Cu (001) surface. Physical Review B. 1995;52:14911.

[9] Suen J-S, Erskine J L. Magnetic hysteresis dynamics: thin p (1× 1) Fe films on flat and stepped W (110). Physical review letters. 1997;78:3567.

[10] Fan Z, Jinxiu Z, Xiao L. Scaling of hysteresis in the Ising model and cell-dynamical systems in a linearly varying external field. Physical Review E. 1995;52:1399.

[11] Acharyya M, Chakrabarti B K. Monte Carlo study of hysteretic response and relaxation in Ising models. Physica A: Statistical Mechanics and its Applications. 1993;192:471-485.

[12] Luse C N, Zangwill A. Discontinuous scaling of hysteresis losses. Physical Review E. 1994;50:224.

[13] Zhong F, Zhang J X, Siu G G. Dynamic scaling of hysteresis in a linearly driven system. Journal of Physics: Condensed Matter. 1994;6:7785.

[14] Pluta W A. Some properties of factors of specific total loss components in electrical steel. IEEE Transactions on magnetics. 2010;46:322-325.

[15] Chen Y, Pillay P. An improved formula for lamination core loss calculations in machines operating with high frequency and high flux density excitation. In 37th IAS Annual Meeting (Cat No02CH37344). 2002;2;759-766.

[16] Yamamoto K-i, Nakano H, Yamashiro Y. Effect of compressive stress on hysteresis loss of Terfenol-D. Journal of magnetism and magnetic materials. 2003;254:222-224.

[17] Zeng J, Zeng H, Bai B, Yan M. Calculation of hysteresis losses for Terfenol-D ultrasonic transducer. In Second International Conference on Smart Materials and Nanotechnology in Engineering. 2009;7493;749369.

[18] Huang W, Gao C, Li Y, Wang B. Experimental and calculating analysis of high-frequency magnetic energy losses for Terfenol-D magnetostrictive material. IEEE Transactions on magnetics. 2018;54:1-4.

[19] Bozorth R M. Ferromagnetism. 1993. 